\title{
Patient and surgical prognostic factors for inpatient functional recovery following THA and TKA: a prospective cohort study
}

\author{
Nicola A. Hewlett-Smith ${ }^{1,2^{*}} \mathbb{B}$, Rodney P. Pope ${ }^{1,3} \mathbb{B}$, Wayne A. Hing ${ }^{1} \mathbb{B}$, Vini P. Simas ${ }^{1}$ [D and James W. Furness ${ }^{1}$ (D)
}

\begin{abstract}
Background: The introduction of enhanced recovery pathways has demonstrated both patient and organisational benefits. However, enhanced recovery pathways implemented for total hip arthroplasty (THA) and total knee arthroplasty (TKA) vary between health-care organisations, as do their measures of success, particularly patientrelated outcomes. Despite inpatient functional recovery being essential for safe and timely hospital discharge, there is currently no gold standard method for its assessment, and the research undertaken to establish prognostic factors is limited. This study aimed to identify prognostic factors and subsequently develop prognostic models for inpatient functional recovery following primary, unilateral THA and TKA; identify factors associated with acute length of stay; and assess the relationships between inpatient function and longer-term functional outcomes.

Methods: Correlation and multiple regression analyses were used to determine prognostic factors for functional recovery (assessed using the modified lowa Level of Assistance Scale on day 2 post-operatively) in a prospective cohort study of 354 patients following primary, unilateral THA or TKA.
\end{abstract}

Results: For the overall cohort and TKA group, significant prognostic factors included age, sex, pre-operative general health, pre-operative function, and use of general anaesthesia, local infiltration analgesia, and patient-controlled analgesia. In addition, arthroplasty site was a prognostic factor for the overall cohort, and surgery duration was prognostic for the TKA group. For the THA group, significant prognostic factors included pre-operative function, Risk Assessment and Prediction Tool score, and surgical approach. Several factors were associated with acute hospital length of stay. Inpatient function was positively correlated with functional outcomes assessed at 6 months post-operatively.

Conclusions: Prognostic models may facilitate the prediction of inpatient flow thus optimising organisational efficiency. Surgical prognostic factors warrant consideration as potential key elements in enhanced recovery pathways, associated with early post-operative functional recovery. Standardised measures of inpatient function serve to evaluate patientcentred outcomes and facilitate the benchmarking and improvement of enhanced recovery pathways.

Keywords: Total hip arthroplasty, Total knee arthroplasty, Prognostic factors, Predictors, Inpatient function, Functional recovery

\footnotetext{
* Correspondence: Nicola.hewlett-smith@student.bond.edu.au

${ }^{1}$ Faculty of Health Sciences and Medicine, Bond University, Gold Coast, Australia

${ }^{2}$ Nicola Hewlett-Smith Allied Health Department, The Wesley Hospital, PO Box 499, Brisbane 4066, Australia

Full list of author information is available at the end of the article
}

(c) The Author(s). 2020 Open Access This article is licensed under a Creative Commons Attribution 4.0 International License, which permits use, sharing, adaptation, distribution and reproduction in any medium or format, as long as you give appropriate credit to the original author(s) and the source, provide a link to the Creative Commons licence, and indicate if changes were made. The images or other third party material in this article are included in the article's Creative Commons licence, unless indicated otherwise in a credit line to the material. If material is not included in the article's Creative Commons licence and your intended use is not permitted by statutory regulation or exceeds the permitted use, you will need to obtain permission directly from the copyright holder. To view a copy of this licence, visit http://creativecommons.org/licenses/by/4.0/ The Creative Commons Public Domain Dedication waiver (http://creativecommons.org/publicdomain/zero/1.0/) applies to the data made available in this article, unless otherwise stated in a credit line to the data. 


\section{Background}

The rising prevalence of osteoarthritis, in Australia and other developed countries, has seen a corresponding rise in primary total hip arthroplasty (THA) and primary total knee arthroplasty (TKA) over the past two decades [1]. Since its inception in 2003, the Australian National Joint Replacement Registry has reported an increase in primary THA and TKA procedures of $108.1 \%$ and $156.2 \%$ respectively [2]. The increasing burden of these elective procedures has implications for health care costs and resources [1]; therefore, efficient provision of quality patient care is a priority. As such, enhanced recovery pathways (ERP) have been applied to several surgical procedures, including THA and TKA, to improve and streamline the delivery of patient care and reduce hospital length of stay (LOS).

Initially described by Kehlet [3], ERP aim to prepare patients for surgery, reduce the negative impact of surgery, and facilitate a more rapid recovery. Every step of the surgical journey, pre-operatively to post-operatively, is examined, rationalised, optimised, and standardised, resulting in a streamlined care pathway combining evidence-based clinical features with optimal organisational efficiency [4].

Although components of THA and TKA ERP have been identified, and recommendations put forward, the level of evidence supporting each of these recommendations is variable [5]. Currently, no standardised guidelines apply to each ERP component, which would more readily facilitate implementation [6]. The lack of defined guidelines, and the numerous components that ERP contain, means that successful implementation requires multidisciplinary consensus at an organisational level [6]. Achieving consensus to enable a standardised approach for each ERP component may prove challenging in many healthcare facilities. ERP literature reviews have suggested that future research should focus on understanding which pathway components contribute to improved recovery [7] and quantifying the impact of individual variables [8]. An understanding of which variables are most associated with early post-operative functional recovery may direct attention to particular pathway components, thus further improving ERP outcomes.

A recent systematic review [9] examined the prognostic relationships between patient and surgical factors and early post-operative functional recovery assessed using validated outcome measures. The review found strong evidence that comorbidity status (determined by American Society of Anaesthesiologists, ASA grade) and preoperative function (assessed by the Timed Up and Go test, TUG) are prognostic for inpatient functional recovery following TKA. No such evidence was found for patient-related prognostic factors for inpatient recovery following THA, and no surgical factors were found to be independently prognostic for inpatient recovery following either procedure. However, limited evidence did suggest ERP may facilitate functional recovery in the TKA population. None of the studies included in the review collected data within the last 5 years, and therefore, the potential impacts of more recent surgical advances including muscle-sparing approaches and robot-assisted surgery were not assessed.

Thus, the primary aims of this study were to examine the relationships between patient-related and surgical factors and inpatient functional recovery following THA and TKA, where functional recovery was assessed using validated functional performance measures appropriate to the early post-operative period, and, based on these findings, to develop prognostic models for inpatient functional recovery. Secondary aims were to identify patient-related, surgical, or post-operative factors associated with acute hospital LOS and to assess the relationships between functional performance measures assessed on the 2nd post-operative day (POD) and longer-term (6-month) patient-reported functional outcomes following THA and TKA.

\section{Methods}

\section{Research design and setting}

This prospective cohort study was conducted at The Wesley Hospital, Brisbane, an Australian privately funded, not for profit hospital. The ERP applied to this patient cohort is partially standardised, allowing for individual preferences of surgeons and anaesthetists. Ethics approval was obtained for this study from the Uniting Care Human Research Ethics Committee (HREC no. 2016.09.187) and Bond University Human Research Ethics Committee (HREC no. 15685).

\section{Participants}

All patients undergoing elective, primary, unilateral THA and TKA between 1 May 2018 and 30 April 2019 were considered for inclusion. Potential participants were provided with information about the study for consideration prior to their attendance at pre-admission clinic, where eligibility criteria were applied and written informed consent was obtained. Patients were excluded if they were undergoing uni-compartmental, bilateral, or revision arthroplasty; not reviewed pre-operatively or unable to perform the assessments of pre-operative function; considered inappropriate to participate in the existing ERP due to multiple complex comorbidities; or identified to have significant language or cognitive barriers. A two-stage screening process was used to confirm adequate cognitive function (Appendix 1). The first stage involved verbal screening in the pre-admission clinic by an occupational therapist, and a Mini-Mental State Examination (MMSE) [10] was performed for any 
potential participants who reported difficulty with memory or cognition. Secondly, an MMSE was undertaken for any participants whom the treating physiotherapist observed poor recall or carry-over between treatment sessions, which appeared to be limiting post-operative progression. The exclusion criteria were devised to ensure homogeneity of participants with regard to preoperative education and surgical procedure and to exclude patients with factors reasonably considered to influence their ability to follow usual instruction or participate in the usual post-operative physiotherapy care as part of the existing ERP. All patients received usual pre-operative and post-operative care regardless of their participation in the study, with the only difference being that data pertaining to the potential prognostic factors were extracted from the medical charts of participants.

\section{Prognostic factors}

Patient-related factors (Table 2) and potentially modifiable peri-operative and post-operative factors (Table 3 ) associated with the existing ERP were selected as the potential prognostic factors to be investigated.

\section{Outcome measures}

\section{Primary outcome measure}

The primary outcome measure was inpatient functional recovery assessed on POD 2 using the modified Iowa Level of Assistance Scale (mILAS) [11]. The mILAS (Appendix 2) is an easily performed 6-item functional performance measure that assesses 4 activities of daily living (ADL; supine to sitting, sit to stand, walking, and negotiation of a single step), walking distance, and required mobility aid. Each item is scored 0-6, with a maximum possible total score of 36 ; higher scores indicate greater functional dependence. The mILAS has demonstrated validity in assessing readiness for discharge, with a statistically significant difference in median scores of 17 points observed between patients considered ready for discharge (median score 0, IQR 0-4.25) and those deemed not yet ready for discharge (median score 17, IQR 12-23) [11]. The mILAS is responsive, with a minimal detectable change (MDC) of 5.8 points and large changes in scores typically evident over the course of an acute hospital admission; furthermore, it has excellent inter-rater reliability (intraclass correlation coefficient; ICC $=0.975$ ) [11].

\section{Secondary outcome measures}

Timed Up and Go test, 10-metre walk test POD 2 inpatient functional recovery was also assessed using the Timed Up and Go (TUG) test [12] and 10-metre walk test (10mWT) [13]. The TUG is a reliable test of functional mobility in patients following TKA, with excellent test-retest reliability $(\mathrm{ICC}=0.98)$ and a MDC of $2.27 \mathrm{~s}$ [14], and has been demonstrated to predict both shortterm $[15,16]$ and long-term function following lower limb arthroplasty $[17,18]$. The $10 \mathrm{mWT}$ is a reliable measure of gait speed [19]. For both the TUG and $10 \mathrm{mWT}$, a higher score (in seconds) indicates a slower gait speed, and each is an independent predictor of general health decline, ADL difficulty, and falls, in older community-dwelling adults [20].

Longer-term functional outcomes Longer-term functional outcomes were assessed using patient-reported outcome measures (PROM), including the Oxford Hip Score (OHS) [21] or Oxford Knee Score (OKS) [22], and the EuroQol-5 Dimension visual analogue scale (EQ-5D VAS) [23], each administered by telephone. The OHS and OKS are joint-specific PROM designed to assess pain behaviour and ability to perform ADL following THA and TKA, with higher scores indicating greater function [24]. The OHS and OKS have undergone extensive reliability and validity testing [24] and have been used in multiple studies, to benchmark arthroplasty outcomes in the UK and Australian National Joint Replacement Registries. The minimal important changes (MIC) for assessment at the group level are 11 and 9 points for the OHS and OKS, respectively [25]. For assessment of individual patients, the MIC are 8 and 7 points for the OHS and OKS, respectively [25]. The distribution-based minimal detectable change (MDC90) estimates were 5 and 4 points, for the OHS and OKS, respectively [25]. The English language versions, adapted for use in Australia, were used in this study, and scoring was undertaken per the respective user guides [26, 27].

The EQ-5D-5L is a widely used PROM designed to provide a simple, generic measure of health [23]. The VAS component comprises a 20 -cm vertical scale numbered from 0 to 100, 0 indicating "the worst health you can imagine" and 100 "the best health you can imagine". Participants scoring less than 100 were asked to identify the aspect of their health responsible for generating the response. This was in order to distinguish whether the site of arthroplasty (or another aspect of general health) was the primary factor impacting their score on the EQ5 D VAS. It has previously been demonstrated that TKA functional outcomes measured using the OKS at 12 months post-operatively [28] were influenced by postoperative general physical health. As such, the EQ-5D VAS was used to assess general health as a potential contributor to functional outcomes of the participants.

Length of stay Length of stay (LOS) was calculated as the number of nights spent in the acute hospital setting. 
Despite previous studies indicating that LOS is influenced by many factors other than the physical function of the patient [29-34], LOS remains a commonly used outcome measure for evaluating the success of ERP and benchmarking performance amongst healthcare organisations and thus was recorded for completeness.

\section{Procedure}

All participants underwent primary, unilateral TKA or THA procedures and received usual pre- and postoperative care in The Wesley Hospital, consistent with the existing ERP, under the direction of their treating surgeon and independent of the research. Usual physiotherapy care involved day of surgery (DOS) mobilisation (as appropriate), bidaily physiotherapy on POD 1-3 (including weekends), and daily physiotherapy on subsequent days (at the discretion of the treating physiotherapist) until time of discharge or transfer to inpatient rehabilitation. Physiotherapy incorporated range of motion and strengthening exercises, transfer practice, gait re-education, progression of mobility aids and distances walked, stairs practice, and discharge planning.

Assessments of function were undertaken at predetermined time points (Table 1). Pre-operative function was assessed 1-4 weeks pre-operatively during a usual pre-admission appointment. Assessments of postoperative function were conducted during usual postoperative physiotherapy care, on the afternoon of POD 2 , and on the morning of discharge from the

Table 1 Time points for assessment of pain and functional measures

\begin{tabular}{|c|c|}
\hline Time point & Assessments of pain and function \\
\hline \multirow[t]{6}{*}{ Pre-admission clinic } & $\begin{array}{l}\text { EuroQol-5 Dimension Visual Analogue } \\
\text { Scale }\end{array}$ \\
\hline & Oxford Hip or Knee Score \\
\hline & Visual analogue scale \\
\hline & Modified lowa Level of Assistance Scale \\
\hline & Timed Up and Go \\
\hline & 10-metre walk test \\
\hline \multirow[t]{4}{*}{ Post-operative day 2} & Visual analogue scale \\
\hline & Modified lowa Level of Assistance Scale \\
\hline & Timed Up and Go \\
\hline & 10-metre walk test \\
\hline \multirow[t]{4}{*}{ Day of discharge } & Visual analogue scale \\
\hline & Modified lowa Level of Assistance Scale \\
\hline & Timed Up and Go \\
\hline & 10-metre walk test \\
\hline \multirow[t]{2}{*}{$\begin{array}{l}\text { Six months post-operative } \\
\text { ( } 50 \% \text { of cohort only) }\end{array}$} & $\begin{array}{l}\text { EuroQol-5 Dimension Visual Analogue } \\
\text { Scale }\end{array}$ \\
\hline & Oxford Hip or Knee Score \\
\hline
\end{tabular}

orthopaedic ward. The TUG and 10mWT were assessed at each time point only if the participant was judged to be able to perform the test safely and independently (using their customary mobility aid). For both the TUG and the $10 \mathrm{mWT}$, time was recorded with a stopwatch (in seconds), and participants were instructed to perform the tests as quickly as possible, without compromising their safety. At each time point, two TUG trials were completed, and the faster of the two times was recorded. For the $10 \mathrm{mWT}$, only one trial was assessed at each time point. For the mILAS, participants were scored based on the same mobility aid they used when performing the TUG and 10mWT.

A data collection form was devised to record the potential prognostic factors and the results of outcome measures for each participant. Information was entered into a secure database, and subsequently, all participants were de-identified prior to data analysis. Patient factors were recorded during a pre-operative subjective assessment; surgical and post-operative factors were extracted from the patient medical chart. Discharge date was recorded and defined as the date each participant was discharged from the acute orthopaedic ward to a suitable home environment or to inpatient rehabilitation. Patient readiness to discharge home was mutually determined by the patient and treating surgeon, with guidance from the treating physiotherapist based on ERP discharge criteria (Appendix 3) and independent of the research. Admission to inpatient rehabilitation was based on consideration of patients' post-operative medical or functional status and availability of appropriate social support, and independent of the research.

Data collection and assessment of all outcome measures were conducted by qualified physiotherapy staff. If participants were unable to perform any of the functional assessments at a particular time point (Table 1), the reason for this was recorded. Longer-term functional outcomes were assessed via telephone interview at 6 months post-operatively, for participants who comprised the first half of the study cohort.

\section{Statistical analysis}

A recruitment target of 350 participants was planned for the study, based on power calculations conducted using G*Power software (version 3.1.9.2, 2014). This number of participants allowed sufficient numbers to ensure statistical power of at least $80 \%$ to detect small to moderate levels of association between the prognostic factors of interest and the primary outcome measure, if such existed in the underlying population, using multiple linear regression analyses and a significance level of 0.05 .

All statistical analyses were conducted using SPSS (IBM, version 26, 2019). Descriptive analyses were first 
conducted to describe the study cohort and variables of interest and to identify missing values. Distributions of all continuous prognostic factors and outcome measures were assessed, with normality and outliers assessed via visual inspection of histograms, box plots, and normal QQ plots, to inform decisions regarding the removal of outliers and approaches to statistical analysis. Independent samples $t$ tests, Mann-Whitney $U$ tests, and chisquare tests were used, as appropriate based on variable types and distributions, to assess baseline differences between the two surgical groups (TKA and THA) in demographics, other prognostic factors, and outcome measures.

To enable assessment of the linearity or other form of relationships between continuous prognostic and outcome variables and so inform decision-making about whether linear regression analyses would be appropriate to use to assess prognostic relationships, simple error bar charts were developed and visually inspected. For this purpose, continuous prognostic factors were first categorised into equal intervals, and then, where needed to ensure at least 10 participants in each category, two or more categories at either or both ends of the range of values for each variable were collapsed to form single categories.

Where linearity of relationships was evident, correlations between each of the ordinal or continuous prognostic factors and POD 2 mILAS were determined using Pearson's and Spearman's correlation analyses, as appropriate. Relationships between each of the nominal (dichotomous) prognostic factors and POD 2 mILAS were assessed using point biserial correlation analyses. Only prognostic factors that were significantly associated with POD 2 mILAS at the 0.1 level of statistical significance were included in subsequent multiple linear regression analyses. Nominal prognostic factors with sub-groups of less than 30 participants were also excluded from subsequent analyses due to the impacts of small sub-groups on statistical power to detect associations.

Prior to the conduct of multiple linear regression modelling, Pearson's correlation analyses were undertaken to identify collinearity among continuous prognostic factors. Similarly, point biserial correlation analyses were undertaken to determine whether any dichotomous prognostic factors were substantially correlated with the continuous prognostic factors. Pairs of factors for which the correlation analyses yielded $r>0.7$ were identified, and in any such instances, one of the two correlated factors was removed from the subsequent regression analyses, based on pragmatic considerations which were recorded. Backward, stepwise, multiple linear regression analysis was then used to determine the combination of prognostic factors that best predicted POD 2 mILAS, with the level of statistical significance set at 0.05 for retention of any prognostic factor in the final regression model. Regression models were determined in this way for the whole cohort and separately for each of the THA and TKA cohorts.

\section{Results}

The patient and participant flow through the study is depicted in Fig. 1.

Descriptive statistics for patient characteristics assessed pre-operatively are presented in Table 2 . Statistically significant differences existed between THA and TKA groups for mean body mass index (BMI) $(p=0.002)$, ASA grade distribution $(p<0.001)$, patient-reported preoperative function as determined by mean OHS or OKS scores $(p=0.02)$, and mean Risk And Prediction Tool (RAPT) score $(p=0.03)$. However, with the exception of ASA grade distributions, these differences were not of a sufficient magnitude to be considered clinically important.

Descriptive statistics for surgical prognostic factors extracted from medical records are presented in Table 3. A statistically significant difference was identified between THA and TKA groups only for anaesthetic method-general anaesthetic (GA) only $(p=0.04)$.

\section{Primary outcome measure POD 2 mILAS}

For the overall cohort, POD 2 mILAS scores ranged from 0 to 27 , with a mean score $( \pm$ SD) of $11.34( \pm 6.2)$ points, and there were no missing values. The mean score for the THA group was $9.85( \pm 6.0)$ and for the TKA group $12.06( \pm 6.1)$, giving a statistically significant mean difference between the 2 groups of 2.21 points (95\% CI, 0.85, 3.57), $t(352)=3.187, p=0.02$. Linearity was established for the relationships between POD 2 mILAS and all continuous and ordinal prognostic factors. However, following visual inspection of boxplots, three significant outliers were identified, and these participants were removed from further analysis with reasons recorded (Fig. 1). The levels of association between the individual prognostic factors and POD2 mILAS scores are presented in Table 4.

BMI, pre-operative pain (VAS), tourniquet duration, tourniquet pressure, oral analgesia only, TKA surgical approach, single-shot regional block, and regional block infusion were excluded from the subsequent regression analyses as no statistically significant association was identified between these prognostic factors and POD 2 mILAS scores at the 0.1 level of significance. ASA grade was not included in the regression model due to too few case numbers in ASA grades 1 and 4. Instead, Spearman's correlation analysis was used to gauge the strength of the relationship between ASA grade and POD 2 mILAS scores, and a weak but statistically significant positive correlation $\left(r_{S}=0.17\right.$ (329), $\left.p=0.002\right)$ was 


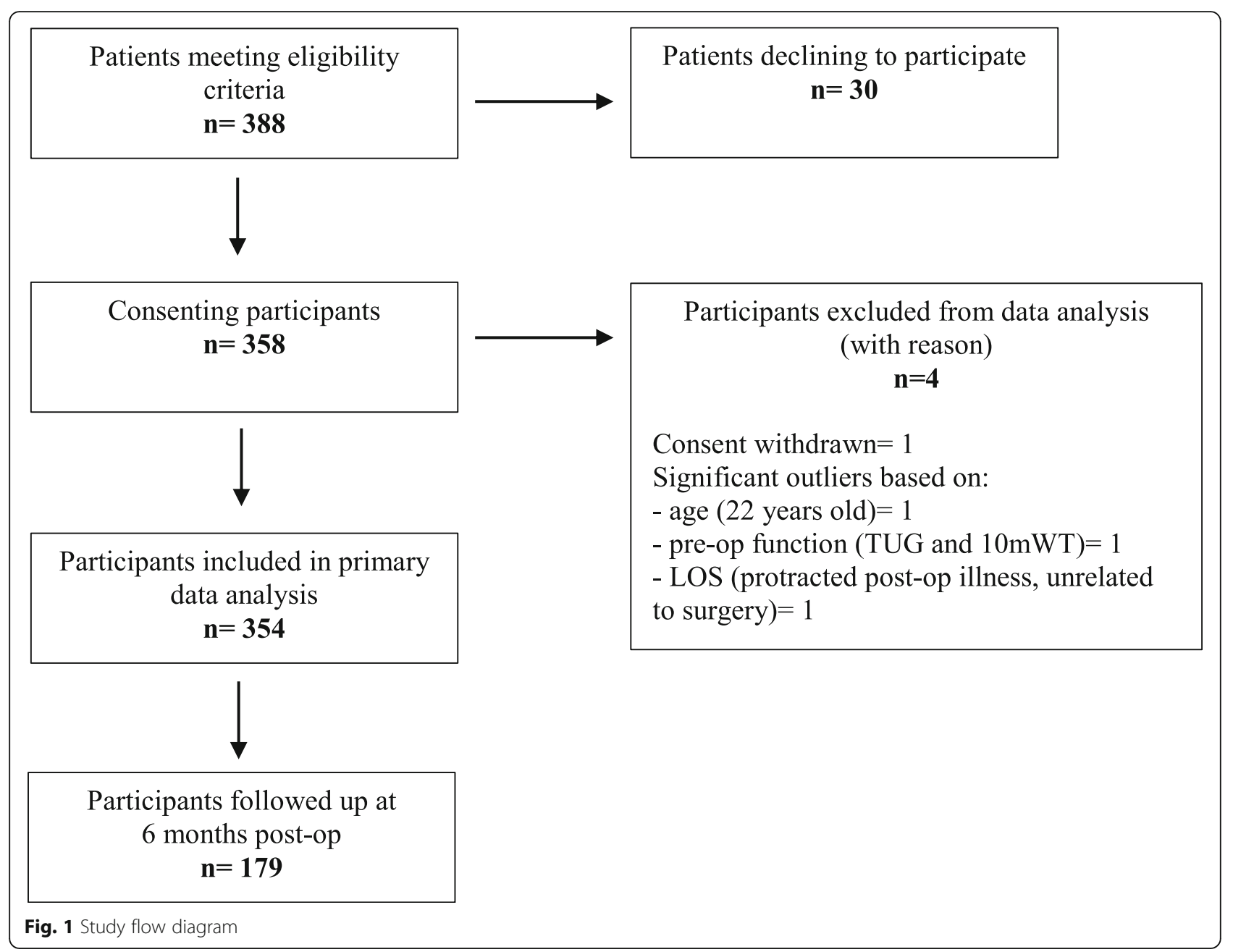

identified. Robot-assisted surgery was removed from TKA and THA analyses due to too few participants having undergone this type of surgery, once the cohort was split by surgical type. Pre-operative TUG time and preoperative 10mWT time were highly correlated, $r=$ 0.880 , and so, the prognostic factor pre-operative $10 \mathrm{mWT}$ was not included in the subsequent regression analyses. This decision to remove the 10mWT rather than TUG from the subsequent regression analyses was made due to variation within the literature regarding the methodology of the 10mWT [35], and thus, its implementation in clinical practice was considered to be potentially less standardised than implementation of the TUG.

The final regression model for prediction of POD 2 mILAS scores in the overall combined TKA and THA cohort, based on significant prognostic factors, is depicted in Table 5, with $R^{2}$ of $34.7 \%$ and adjusted $R^{2}$ of $33.1 \%$, reflecting a medium effect size [36], and with $F(8$, $329)=21.882, p<0.001$. POD 2 mILAS scores (i.e. level of functional dependence of the patient) increased an average of 0.20 points for every year of age, after the other significant prognostic factors were considered (Table 5). POD 2 mILAS scores were on average 1.67 points higher for females than males and decreased an average of 0.05 points for every additional point reported on the EQ-5D VAS general health scale (Table 5). Preoperative TUG time was a further significant prognostic factor, with POD 2 mILAS scores increasing on average 0.45 points for every additional second a patient required to complete the TUG (Table 5). Among the surgical factors, arthroplasty site was a significant prognostic factor, with POD 2 mILAS scores on average 2.21 points higher in patients who underwent a TKA rather than a THA procedure (Table 5). POD 2 mILAS scores were on average 2.07 points lower in patients who received general anaesthesia (GA) only, when compared to those who received other forms of anaesthesia (Table 5). Similarly, POD 2 mILAS scores were on average 3.02 points lower in patients who received local infiltration analgesia (LIA), when compared to those patients who did not, and POD 2 mILAS scores were on average 2.02 points higher in 
Table 2 Descriptive statistics. Patient characteristics, assessed pre-operatively

\begin{tabular}{|c|c|c|c|c|}
\hline Patient characteristic & Total cohort, $N=354$ & TKA, $n=238(67.2 \%)$ & THA, $n=116(32.8 \%)$ & $p$ value \\
\hline Age (years), mean (SD) & $68.9(9.2)$ & $69.5(8.9)$ & $67.7(9.9)$ & 0.09 \\
\hline Sex, $N(\%)$ & & & & 0.30 \\
\hline Female & $185(52.0 \%)$ & $129(54.2 \%)$ & $56(48.3 \%)$ & \\
\hline Male & $169(48.0 \%)$ & $109(45.8 \%)$ & $60(51.7 \%)$ & \\
\hline \multicolumn{5}{|l|}{ BMI $\left(\mathrm{kg} / \mathrm{m}^{2}\right)$} \\
\hline Median (IQR) & $30.0(26.6,33.6)$ & $30.3(27.0,34.5)$ & $28.4(26.1,31.3)$ & $0.002^{*}$ \\
\hline Range & $\begin{array}{l}\text { (18.1-48.8) } \\
\text { Missing: } n=1(0.3 \%)\end{array}$ & $(18.1-48.8)$ & $(18.9-45.8)$ & \\
\hline \multicolumn{5}{|l|}{ ASA grade, $N(\%)$} \\
\hline 1 & $27(8.2 \%)$ & $12(5.5 \%)$ & $15(13.5 \%)$ & $<0.001^{*}$ \\
\hline 2 & $180(54.4 \%)$ & $111(50.5 \%)$ & $69(62.2 \%)$ & \\
\hline 3 & $122(36.9 \%)$ & $97(44.1 \%)$ & $25(22.5 \%)$ & \\
\hline 4 & $2(0.6 \%)$ & $0(0 \%)$ & $2(1.8 \%)$ & \\
\hline Median (IQR) & $\begin{array}{l}2(2,3) \\
\text { Missing: } n=23(6.5 \%)\end{array}$ & $2(2,3)$ & $2(2,2)$ & \\
\hline \multicolumn{5}{|l|}{ Pre-operative $\mathbf{H b}$ (g/L) } \\
\hline Mean (SD) & $\begin{array}{l}137.9(11.8) \\
\text { Missing: } n=4(1.1 \%)\end{array}$ & $137.5(11.6)$ & $138.7(12.1)$ & 0.40 \\
\hline Pre-operative pain (VAS $0-100$ ) & & & & 0.05 \\
\hline Mean (SD) & $\begin{array}{l}38.9(26.3) \\
\text { Missing: } n=6(1.7 \%)\end{array}$ & $37.0(26.7)$ & $42.8(25.0)$ & \\
\hline \multicolumn{5}{|l|}{ Pre-operative function } \\
\hline \multicolumn{5}{|l|}{ OKS/OHS (0-48) } \\
\hline Mean (SD) & $\begin{array}{l}25.5(8.0) \\
\text { Missing: } n=2(0.6 \%)\end{array}$ & $26.0(8.0)$ & $23.7(7.9)$ & $0.02^{*}$ \\
\hline \multicolumn{5}{|l|}{ EQ-5D VAS $(0-100)$} \\
\hline Median (IQR) & $80(70,90)$ & $80(70,90)$ & $80(65,90)$ & 0.11 \\
\hline Range & $\begin{array}{l}\text { (10-100) } \\
\text { Missing: } n=4(1.1 \%)\end{array}$ & $(10-100)$ & $(18-100)$ & \\
\hline \multicolumn{5}{|l|}{ mILAS (0-36) } \\
\hline Median (IQR) & $0(0.0,0.0)$ & $0(0.0,0.0)$ & $0(0.0,0.0)$ & 0.16 \\
\hline Range & $(0-11)$ & $(0-11)$ & $(0-11)$ & \\
\hline \multicolumn{5}{|l|}{ TUG (s) } \\
\hline Median (IQR) & $8.79(7.41,11.09)$ & $8.76(7.58,11.05)$ & $8.98(7.17,11.28)$ & 0.56 \\
\hline Range & $(4.39-30.93)$ & $(4.97-29.29)$ & (4.39-30.93) & \\
\hline \multicolumn{5}{|l|}{ 10mWT (s) } \\
\hline Median (IQR) & $7.61(6.49,9.40)$ & $7.65(6.52,9.40)$ & $7.58(6.44,9.42)$ & 0.71 \\
\hline Range & $(4.23-27.02)$ & $(4.23-22.94)$ & $(4.75-27.02)$ & \\
\hline \multicolumn{5}{|l|}{ RAPT score } \\
\hline Mean (SD) & $\begin{array}{l}9.48 \text { (2.1) } \\
\text { Missing: } n=5(1.4 \%)\end{array}$ & $9.3(2.2)$ & $9.8(2.0)$ & $0.03^{*}$ \\
\hline
\end{tabular}

Missing data: was omitted during pre-admission assessment or could not be extracted from patient medical chart

ASA American Society of Anaesthesiologists, BMI body mass index, EQ-5D VAS EuroQol-5 Dimension Visual Analogue Scale, Hb haemaglobin, IQR inter-quartile range, mILAS modified lowa Level of Assistance Scale, OKS Oxford Knee Score, OHS Oxford Hip Score, RAPT Risk Assessment and Prediction Tool, THA total hip arthroplasty, TKA total knee arthroplasty, TUG Timed Up and Go test, VAS visual analogue scale, 10mWT ten-metre walk test

*Statistical significance assessed at the 0.05 level. $p$ values were derived from an independent-samples $t$-test, Mann-Whitney $U$ test, or chi-square test comparing TKA and THA cohorts, as appropriate for variable type 
Table 3 Descriptive statistics. Surgical prognostic factors

\begin{tabular}{|c|c|c|c|c|}
\hline Surgical factor & Total cohort, $N=354$ & TKA, $n=238(67.2 \%)$ & THA, $n=116(32.8 \%)$ & $p$ value \\
\hline Tourniquet duration & & & & $\mathrm{N} / \mathrm{A}$ \\
\hline (mean $[S D]$ min) & & $\begin{array}{l}59.0(21.5) \\
n=231 \text { (missing } n=7)\end{array}$ & & \\
\hline Tourniquet pressure & & & & N/A \\
\hline (mean $[\mathrm{SD}] \mathrm{mmHg}$ ) & & $\begin{array}{l}292.5(29.1) \\
n=231(\text { missing } n=3)\end{array}$ & & \\
\hline Surgical approach, $N(\%)$ & & & & N/A \\
\hline Parapatellar TKA & & $228(95.8 \%)$ & & \\
\hline Subvastus TKA & & $10(4.2 \%)$ & & \\
\hline Posterior approach THA & & & $71(61.2 \%)$ & \\
\hline Direct anterior approach THA & & & $22(19.0 \%)$ & \\
\hline Direct superior approach THA & & & $23(19.8 \%)$ & \\
\hline Robot-assisted surgery, $N(\%)$ & & & & 0.16 \\
\hline No & $318(89.8 \%)$ & $210(88.2 \%)$ & $108(93.1 \%)$ & \\
\hline Yes & $36(10.2 \%)$ & $28(11.8 \%)$ & $8(6.9 \%)$ & \\
\hline Duration of surgery (min) & & & & 0.67 \\
\hline Median (IQR) & $79(70,93)$ & $79(71,91)$ & $79(67,100)$ & \\
\hline Range & $(37-178)$ & $(37-178)$ & $(49-167)$ & \\
\hline \multicolumn{5}{|l|}{ Anaesthetic method, $N(\%)$} \\
\hline GA only & $97(27.4 \%)$ & $57(23.9 \%)$ & $40(34.5 \%)$ & $0.04^{*}$ \\
\hline$G A+$ spinal $L A$ & $198(55.9 \%)$ & $145(60.9 \%)$ & $53(45.7 \%)$ & 0.07 \\
\hline Sedation + spinal LA & $55(15.5 \%)$ & $34(14.3 \%)$ & $21(18.1 \%)$ & 0.35 \\
\hline Other (intrathecal morphine) & $4(1.1 \%)$ & $2(0.8 \%)$ & $2(1.7 \%)$ & N/A \\
\hline \multicolumn{5}{|l|}{ Initial analgesia, $N(\%)$} \\
\hline Intra-operative LIA & $294(83.1 \%)$ & $214(89.9 \%)$ & $80(69.0 \%)$ & $<0.001^{*}$ \\
\hline PCA & $76(21.5 \%)$ & 49 (20.6\%) & $27(23.3 \%)$ & 0.56 \\
\hline Oral analgesia only & $27(7.6 \%)$ & $7(2.9 \%)$ & $20(17.2 \%)$ & $<0.001^{*}$ \\
\hline Intra-articular catheter & & $113(47.5 \%)$ & N/A & \\
\hline Single-shot regional block & & $31(13.0 \%)$ & N/A & \\
\hline Ambulatory regional block & & $25(10.5 \%)$ & N/A & \\
\hline
\end{tabular}

Missing data: could not be extracted from patient medical chart

GA general anaesthesia, IQR inter-quartile range, LA local anaesthesia, LIA local infiltration analgesia, PCA patient-controlled analgesia, THA total hip arthroplasty, TKA total knee arthroplasty

* Statistical significance assessed at the 0.05 level. $p$ values were derived from an independent-samples $t$ test, Mann-Whitney $U$ test, or chi-square test comparing TKA and THA cohorts, as appropriate for variable type

patients who received post-operative analgesia via patientcontrolled analgesia (PCA) when compared to those patients who did not (Table 5).

The final regression model for prediction of POD 2 mILAS scores in the TKA group, based on significant prognostic factors, is depicted in Table 6, with $R^{2}$ of $36.4 \%$ and adjusted $R^{2}$ of $34.1 \%$, reflecting a medium effect size [36], and with $F(8,220)=15.723, p<0.001$. POD 2 mILAS scores increased on average 0.18 points for every year of age and were on average 1.49 points higher for females than males (Table 6). POD 2 mILAS scores decreased on average 0.09 points for every additional point reported on the EQ-5D VAS general health scale, and similarly increased an average of 0.50 points for every additional second a patient required to complete the TUG (Table 6). POD 2 mILAS scores were on average 2.07 points lower in patients who received a GA only, when compared to those who received other forms of anaesthesia (Table 6). POD 2 mILAS scores were on average 3.62 points lower in patients who received LIA, when compared to those patients who did not, and POD 2 mILAS scores were on average 2.35 points higher in patients who received post-operative analgesia via PCA when compared to those patients who did not (Table 6). POD 2 mILAS scores were also on average 0.03 points lower for every additional minute of surgical time (Table 6). 
Table 4 Correlation between individual potential prognostic factors and POD 2 mILAS scores

\begin{tabular}{|c|c|c|}
\hline Potential prognostic factors & $r$ or $r_{s}$ & $p$ value \\
\hline \multicolumn{3}{|l|}{ Patient-related factors } \\
\hline Age & 0.34 & $<0.001^{*}$ \\
\hline Pre-operative $\mathrm{Hb}$ & -0.19 & $<0.001^{*}$ \\
\hline RAPT score & -0.39 & $<0.001^{*}$ \\
\hline $\begin{array}{l}\text { Pre-operative patient-reported function } \\
\text { (OKS/OHS) }\end{array}$ & -0.16 & $<0.001^{*}$ \\
\hline Pre-operative function (mILAS) & 0.20 & $<0.001^{*}$ \\
\hline Pre-operative function (TUG) & 0.33 & $<0.001^{*}$ \\
\hline Pre-operative function (10mWT) & 0.34 & $<0.001^{*}$ \\
\hline Gender $(0=$ female, $1=$ male $)$ & -0.19 & $<0.001^{*}$ \\
\hline ASA & 0.17 & $0.002^{*}$ \\
\hline $\begin{array}{l}\text { Pre-operative patient-reported general health } \\
\text { (EQ-5D VAS) }\end{array}$ & -0.11 & $0.04^{*}$ \\
\hline Pre-operative pain (VAS) & 0.09 & 0.11 \\
\hline BMI & 0.05 & 0.34 \\
\hline \multicolumn{3}{|l|}{ Surgical factors } \\
\hline $\begin{array}{l}\text { Surgical approach (THA cohort only) } \\
(0=\mathrm{PA}, 1=\mathrm{DAA} \text { or DSA })\end{array}$ & -0.37 & $<0.001^{*}$ \\
\hline LIA use & -0.21 & $<0.001^{*}$ \\
\hline Surgery duration & -0.24 & $<0.001^{*}$ \\
\hline PCA use & 0.18 & $0.001^{*}$ \\
\hline Arthroplasty site $(0=\mathrm{THA}, 1=\mathrm{TKA})$ & 0.17 & $0.002^{*}$ \\
\hline Intra-articular catheter (TKA cohort only) & -0.19 & $0.003^{*}$ \\
\hline GA only & -0.13 & $0.02^{*}$ \\
\hline Sedation and spinal anaesthesia & 0.09 & $0.09^{*}$ \\
\hline Robot-assisted surgery & -0.09 & $0.09^{*}$ \\
\hline Single-shot regional block (TKA cohort only) & 0.08 & 0.21 \\
\hline Oral analgesia only & 0.06 & 0.25 \\
\hline GA and spinal anaesthesia & 0.03 & 0.53 \\
\hline $\begin{array}{l}\text { Surgical approach (TKA cohort only) } \\
(1=\text { parapatellar approach, } 2 \text { = subvastus approach) }\end{array}$ & -0.04 & 0.54 \\
\hline Ambulatory regional block (TKA cohort only) & 0.04 & 0.57 \\
\hline Tourniquet pressure (TKA cohort only) & -0.02 & 0.76 \\
\hline Tourniquet duration (TKA cohort only) & -0.02 & 0.80 \\
\hline
\end{tabular}

ASA American Society of Anaesthesiologists, BMI body mass index, DAA direct anterior approach, DOS day of surgery, DSA direct superior approach, EQ-5D VAS EuroQol-5 Dimension Visual Analogue Scale, $\mathrm{Hb}$ haemaglobin, GA general anaesthesia, LIA local infiltration analgesia, mILAS modified lowa Level of Assistance Scale, OKS Oxford Knee Score, OHS Oxford Hip Score, PA posterior approach, PCA patient-controlled analgesia, POD post-operative day, RAPT Risk Assessment and Prediction Tool, THA total hip arthroplasty, TKA total knee arthroplasty, TUG Timed Up and Go test, VAS visual analogue scale, 10mWT ten-metre walk test

*Statistical significance assessed at the 0.1 level. $p$ values were derived from Pearson's correlation, Spearman's correlation, or point biserial correlation, as appropriate for variable type

The final regression model for prediction of POD 2 mILAS scores in the THA group, based on significant prognostic factors, is depicted in Table 7 , with $R^{2}$ of
$32.4 \%$ and adjusted $R^{2}$ of $30.4 \%$, reflecting a medium effect size [36], and with $F(3,105)=16.742, p<0.001$. POD 2 mILAS scores decreased an average of 0.94 points for every additional point scored on the RAPT, after the other significant prognostic factors were considered (Table 7). POD 2 mILAS scores increased on average 0.36 points for every additional second a patient required to complete the TUG (Table 7). THA surgical approach was a further significant prognostic factor, with POD 2 mILAS scores on average 4.67 points higher in patients who underwent THA via a posterior surgical approach when compared to other surgical approaches (direct anterior approach or direct superior approach; Table 7).

Independent samples $t$ tests and chi-square tests revealed no statistically significant differences in age, ASA grade distributions, or measures of pre-operative function, between the THA surgical approach groups-posterior approach (PA) versus direct anterior approach (DAA) or direct superior approach (DSA).

Additional analyses revealed participants who mobilised on the DOS had lower mean POD 2 mILAS scores $(10.43 \pm 5.8)$ than those who first mobilised on POD 1 $(13.64 \pm 6.5)$, with a statistically significant difference of 3.21 points $(95 \% \mathrm{CI}, 1.81,4.61), t(352)=4.513, p<$ 0.001 . In the overall cohort, $49.2 \%$ experienced barriers to post-operative progress (Table 8). Participants who experienced post-operative progress barriers had higher mean POD 2 mILAS scores $(14.65 \pm 5.5)$ than those who did not $(8.13 \pm 5.0)$, with a statistically significant difference of 6.52 points $(95 \% \mathrm{CI},-7.62,-5.42), t(352)$ $=-11.636, p<0.001$.

\section{Secondary outcome measures POD 2 TUG and POD2 10mWT}

In the overall cohort, $75.7 \%$ and $76.3 \%$ of participants completed the POD 2 TUG and $10 \mathrm{mWT}$, respectively. The reasons for non-completion of these outcome measures are as follows: $18.1 \%$ of the cohort failed to meet an appropriate level of functional independence, $2.5 \%$ were inadvertently omitted by the treating therapist, and approximately $3.0 \%$ were limited by symptoms including pain, nausea, dizziness, wound ooze, and diarrohea or were awaiting investigations. Due to the proportion of participants for whom this outcome data was missing, regression analyses were not completed for these outcome measures. However, Spearman's correlation revealed a moderate correlation between POD 2 mILAS scores and scores on each of the secondary outcome measures assessed on POD 2: POD 2 TUG $r(266)=0.48, p<0.001$, and POD 2 10mWT $r(268)=0.39, p<0.001$.

\section{Longer-term (6 months) PROMs}

As planned, 6 months follow-up and collection of data pertaining to longer-term outcomes were completed for 
Table 5 Final prognostic model for post-operative day 2 functional recovery (POD 2 mILAS) in overall cohort

\begin{tabular}{|c|c|c|c|c|c|}
\hline Prognostic factors & $\begin{array}{l}\text { Unstandardized regression } \\
\text { coefficient }(B)\end{array}$ & $\begin{array}{l}\text { Standard error of the } \\
\text { coefficient }\left(\mathrm{SE}_{B}\right)\end{array}$ & $95 \%$ Cl for $B$ & $\begin{array}{l}\text { Standardized } \\
\text { coefficient }(ß)\end{array}$ & $p$ value \\
\hline Constant/intercept & -0.906 & 2.550 & $-5.923,4.111$ & & 0.723 \\
\hline Age & 0.201 & 0.032 & $0.138,0.264$ & 0.297 & $<0.001$ \\
\hline Gender ( 0 = female, 1 = male) & -1.671 & 0.571 & $-2.795,-0.547$ & -0.134 & 0.004 \\
\hline $\begin{array}{l}\text { Pre-operative patient-reported general health } \\
\text { (EQ-5D VAS/100) }\end{array}$ & -0.051 & 0.020 & $-0.090,-0.013$ & -0.126 & 0.009 \\
\hline Pre-operative function (TUG, sec) & 0.453 & 0.094 & $0.269,0.637$ & 0.241 & $<0.001$ \\
\hline Arthroplasty site $(0=\mathrm{THA}, 1=\mathrm{TKA})$ & 2.223 & 0.631 & $0.982,3.464$ & 0.167 & $<0.001$ \\
\hline Anaesthetic - use of GA only & -2.067 & 0.674 & $-3.392,-0.742$ & -0.148 & 0.002 \\
\hline Initial analgesia_LIA use & -3.022 & 0.848 & $-4.690,-1.355$ & -0.184 & $<0.001$ \\
\hline Initial analgesia_-PCA use & 2.021 & 0.765 & $0.516,3.526$ & 0.134 & 0.009 \\
\hline
\end{tabular}

Statistical significance assessed at the 0.05 level

CI confidence interval, EQ-5D VAS EuroQol-5 Dimension Visual Analogue Scale, GA general anaesthesia, LIA local infiltration analgesia, PCA patient-controlled analgesia, TUG Timed Up and Go test, VAS visual analogue scale

179 (50.6\%) of the 354 participants included in the primary analyses. For this sub-group, the changes between baseline measures and measures assessed at 6 months post-operatively are presented in Table 9. The median increases in OHS and OKS scores for the THA and TKA sub-groups, respectively, exceeded the group MICs for these measures of 11 (OHS) and 9 points (OKS) [25] (Table 9). The OHS MIC, for individuals, of 8 points [25] was exceeded by $93.3 \%$ of the THA sub-group. Similarly, $82.9 \%$ of the TKA sub-group exceeded the OKS MIC for individuals of 7 points [25] (Table 9). An increase of only 1 point in the median change score for the EQ-5D VAS (Table 9) indicated that self-reported general health status did not differ significantly between pre-operative assessment and 6 months post-operative assessment for the participants followed up at 6 months post-operatively.
A small, negative statistically significant correlation existed between POD 2 mILAS score and OKS or OHS scores at 6 months post-operatively for the overall subgroup $(r(177)=-0.27, p<0.001)$, and similarly for the TKA sub-group $(r(116)=-0.19, p=0.037)$. A similar small, negative correlation of borderline statistical significance was found for the THA sub-group $(r(59)=$ - 0.25, $p=0.052$ ). The correlation between POD 2 mILAS scores and EQ-5D VAS scores at 6 months postoperatively did not meet statistical significance for any of the studied cohorts.

For the THA sub-group, a moderate, positive, statistically significant correlation existed between $\mathrm{OHS}$ and EQ-5D VAS assessed at 6 months post-operatively $(r(59)$ $=0.39, p=0.002)$, and a non-statistically significant small, positive correlation was found between OKS and EQ-5D VAS assessed at the same time point for the

Table 6 Final prognostic model for post-operative day 2 functional recovery (POD 2 mILAS) for the TKA group

\begin{tabular}{|c|c|c|c|c|c|}
\hline Prognostic factors & $\begin{array}{l}\text { Unstandardized regression } \\
\text { coefficient }(B)\end{array}$ & $\begin{array}{l}\text { Standard error of the } \\
\text { coefficient }\left(\mathrm{SE}_{B}\right)\end{array}$ & $95 \% \mathrm{Cl}$ for $B$ & $\begin{array}{l}\text { Standardized } \\
\text { coefficient ( }(B)\end{array}$ & $\overline{p \text { value }}$ \\
\hline Constant/intercept & 7.837 & 4.187 & $-0.415,16.090$ & & 0.063 \\
\hline Age & 0.184 & 0.042 & $0.101,0.267$ & 0.263 & $<0.001$ \\
\hline Gender ( 0 = female, 1 = male) & -1.487 & 0.696 & $-2.859,-0.116$ & -0.120 & 0.034 \\
\hline $\begin{array}{l}\text { Pre-operative patient-reported general health } \\
\text { (EQ-5D VAS/100) }\end{array}$ & -0.087 & 0.024 & $-0.134,-0.039$ & -0.207 & $<0.001$ \\
\hline Pre-operative function (TUG, sec) & 0.503 & 0.114 & $0.279,0.728$ & 0.263 & $<0.001$ \\
\hline Surgery duration (min) & -0.033 & 0.016 & $-0.064,-0.002$ & -0.125 & 0.038 \\
\hline Anaesthetic method: use of GA only & -2.066 & 0.858 & $-3.756,-0.375$ & -0.143 & 0.017 \\
\hline Initial analgesia: LIA use & -3.619 & 1.193 & $-5.971,-1.267$ & -0.179 & 0.003 \\
\hline Initial analgesia: PCA use & 2.345 & 0.959 & $0.455,4.235$ & 0.154 & 0.015 \\
\hline
\end{tabular}

Statistical significance assessed at the 0.05 level

Cl confidence interval, EQ-5D VAS EuroQol-5 Dimension Visual Analogue Scale, GA general anaesthesia, LIA local infiltration analgesia, PCA patient-controlled analgesia, TUG Timed Up and Go test, VAS visual analogue scale 
Table 7 Final prognostic model for post-operative day 2 functional recovery (POD 2 mILAS) for the THA group

\begin{tabular}{|c|c|c|c|c|c|}
\hline Prognostic actors & $\begin{array}{l}\text { Unstandardized regression } \\
\text { coefficient }(B)\end{array}$ & $\begin{array}{l}\text { Standard error of the } \\
\text { coefficient }\left(\mathrm{SE}_{B}\right)\end{array}$ & $95 \% \mathrm{Cl}$ for $B$ & $\begin{array}{l}\text { Standardized } \\
\text { coefficient }(B)\end{array}$ & $p$ value \\
\hline Constant/intercept & 17.614 & 3.824 & $10.031,25.196$ & & $<0.001$ \\
\hline RAPT score (/12) & -0.943 & 0.278 & $-1.493,-0.392$ & -0.314 & 0.001 \\
\hline Pre-operative function (TUG, sec) & 0.357 & 0.160 & $0.039,0.674$ & 0.205 & 0.028 \\
\hline Surgical approach (0 = PA, $1=\mathrm{DAA}$ or DSA) & -4.671 & 1.016 & $-6.686,-2.656$ & -0.373 & $<0.001$ \\
\hline
\end{tabular}

Statistical significance assessed at the 0.05 level

Cl confidence interval, DAA direct anterior approach, DSA direct superior approach, PA posterior approach, RAPT Risk Assessment and Prediction Tool, THA total hip arthroplasty, TUG Timed Up and Go test

TKA sub-group $(r(116)=0.16, p=0.093) .44 .1 \%$ of the overall sub-group reported health conditions unrelated to the arthroplasty undertaken during the study impacted their EQ-5D VAS assessed at 6 months postoperatively.

\section{LOS}

LOS ranged from 2 to 16 days across all participants, with a median LOS of 4 days for the overall cohort, and for each of the THA and TKA groups. Statistically significant correlations were found between multiple factors and LOS (Table 10). Patient-related factors that were significantly positively correlated with LOS included age, ASA grade, and pre-operative TUG time, $10 \mathrm{mWT}$ time, and mILAS score. Those significantly negatively correlated with LOS were pre-operative RAPT score, EQ-5D VAS, and OKS/OHS scores (Table 10). Surgical and post-operative factors significantly positively correlated with LOS included incidence of postoperative progress barriers and POD 2 mILAS, TUG, and 10mWT scores (Table 10). THA (rather than TKA) surgery, DAA or DSA (rather than PA) THA, use of GA alone, combined use of GA and spinal anaesthesia, intraoperative LIA use, and DOS mobilisation were all associated with shorter LOS than their alternatives (Table 10).

Table 8 Symptoms reported in medical records as impacting post-operative progress in overall cohort

\begin{tabular}{ll}
\hline Progress barriers & $N(\%)$ \\
\hline Pain & $100(28.2 \%)$ \\
Nausea & $47(13.3 \%)$ \\
Dizziness/low BP/pre-syncope & $53(15.0 \%)$ \\
Drowsiness/fatigue & $22(6.2 \%)$ \\
Delirium/impulsiveness & $14(4.0 \%)$ \\
Wound ooze & $12(3.4 \%)$ \\
Anxiety & $12(3.4 \%)$ \\
Constipation & $12(3.4 \%)$ \\
Quads inhibition & $9(2.5 \%)$ \\
Other (including systemically unwell or & $25(7.1 \%)$ \\
medical condition unrelated to surgery) & \\
\hline
\end{tabular}

\section{Discussion}

This study assessed the strengths of the prognostic relationships between patient-related and surgical variables and inpatient functional recovery (as assessed by POD 2 mILAS score) and yielded prognostic models for inpatient functional recovery following THA and TKA. In addition, patient-related, surgical, and post-operative factors associated with hospital LOS were identified, and the relationships between inpatient functional outcomes and longer-term (6-month) patient-reported functional outcomes were assessed. Overall, the findings indicate that a range of patient-related factors assessed preoperatively as well as surgical and post-operative factors were associated with inpatient functional outcomes and with LOS following THA and TKA. In addition, longerterm functional outcomes for these patients reflected their inpatient functional outcomes. These findings address a gap in the existing evidence base, highlight the importance of assessing and optimising functional outcomes in the inpatient period, and may usefully inform the further development of ERP employed for THA and TKA.

The final prognostic models for both the overall cohort and TKA group explained approximately one third of the variance in inpatient functional recovery. Both models included as significant prognostic factors patient age, sex, pre-operative patient-reported general health, pre-operative function (TUG), and GA, LIA, and PCA use. In addition to these factors, arthroplasty site was a prognostic factor for the overall cohort, and surgery duration was prognostic for the TKA group. The final prognostic model for the THA group differed, possibly due in part to the smaller number of THA participants in the overall cohort, and included pre-operative function (TUG time), RAPT score, and surgical approach. Again, the prognostic model developed for the THA group explained approximately one third of the variance in inpatient functional recovery. Importantly, noted in each of the models was the contribution of both patientrelated and surgical factors. This is the first study, to our knowledge, to identify independent, potentially modifiable surgical factors prognostic for early functional recovery following TKA or THA. The recent systematic 
Table 9 Differences in pre-operative and longer-term ( 6 months post-operative) patient-reported outcome measures

\begin{tabular}{|c|c|c|c|c|}
\hline Patient-reported outcome measure & $\begin{array}{l}\text { Baseline score } \\
\text { Median (IQR) } \\
\text { Range, } n\end{array}$ & $\begin{array}{l}6 \text { months post-op score } \\
\text { Median (IQR) } \\
\text { Range, } n\end{array}$ & $\begin{array}{l}\text { Change score } \\
\text { Median (IQR) } \\
\text { Range, } n\end{array}$ & $\begin{array}{l}\text { Change score exceeded MIC } \\
\text { At group level }{ }^{b}, n(\%) \\
\text { For individuals }{ }^{\prime}, n(\%)\end{array}$ \\
\hline OHS & $\begin{array}{l}22.0(17.25,29.0) \\
5-39, n=60\end{array}$ & $\begin{array}{l}46.0(44.0,48.0) \\
22-48, n=61\end{array}$ & $\begin{array}{l}22.5(16.0,28.75) \\
1-42, n=60\end{array}$ & $\begin{array}{l}60(100 \%) \\
56(93.3 \%)\end{array}$ \\
\hline OKS & $\begin{array}{l}25.0(19.0,32.0) \\
7-42, n=117\end{array}$ & $\begin{array}{l}43.0(38.75,46.0) \\
26-48, n=118\end{array}$ & $\begin{array}{l}16.0(9.5,23.0) \\
-4.0-41.0, n=117\end{array}$ & $\begin{array}{l}117(100 \%) \\
97(82.9 \%)\end{array}$ \\
\hline EQ-5D VAS & $\begin{array}{l}80.0(70.0,90.0) \\
25-100, n=178\end{array}$ & $\begin{array}{l}85.0(75.0,90.0) \\
10-100, n=179\end{array}$ & $\begin{array}{l}1.0(-5.0,12.5) \\
-75-50, n=178\end{array}$ & $\mathrm{~N} / \mathrm{A}$ \\
\hline
\end{tabular}

EQ-5D VAS EuroQol-5 Dimension Visual Analogue Scale, IQR inter-quartile range, MIC minimal important change, OHS Oxford Hip Score, OKS Oxford Knee Score ${ }^{a}$ Change score is the difference between pre-operative baseline score and 6 months post-operative score

${ }^{\mathrm{b}}$ For assessment at the group level, an MIC of 11 and 9 points was used for the OHS and OKS, respectively (Beard et al. [28])

${ }^{\mathrm{C}}$ For assessment of individual patients, an MIC of 8 and 7 points was used for the OHS and OKS, respectively (Beard et al. [28])

review conducted by Hewlett-Smith et al. [9] did not find evidence that any individual surgical factors (other than site of arthroplasty) were prognostic for early functional recovery following THA or TKA.

In the prognostic models for both the overall cohort and TKA group, LIA use was associated with greater functional recovery and had the greatest prognostic value in both of these models, whereas PCA use had a negative impact on predicted POD2 mILAS scores. LIA is thought to provide effective early post-operative analgesia (without motor blockade), with less incidence of post-operative complications such as nausea, and a lower requirement for supplemental oral opioids; however, there is only low-level evidence for these effects in THA [37] and TKA [38]. In addition, optimal volume, composition, and site of administration of LIA have not been confirmed [5]. Limiting use of PCA pumps in the routine arthroplasty population is strongly recommended due to associated functional impedance [5]. Although attachments were routinely removed by POD 2 in the current study, PCA use was significantly correlated with post-operative nausea $(p<0.001)$ and dizziness $(p=0.018)$ in the overall cohort, which may explain its association with reduced functional recovery.

Less expected was the association between GA use and greater functional recovery in the overall cohort and TKA group. ERP literature has traditionally supported the use of spinal anaesthesia $[4,39,40]$, although a meta-analysis of 29 studies including 10,488 patients reported no significant difference in the incidence of perioperative complications following THA and TKA when comparing neuraxial and general anaesthesia [41]. However, neuraxial methods were employed in significantly fewer patients than GA, and notably, epidural rather than spinal anaesthesia was the primary mode of neuraxial anaesthesia used [41]. Recently published anaesthesia consensus guidelines have reported low evidence for primary TKA and low to moderate evidence for primary THA in favour of neuraxial anaesthesia versus GA [42]. However, lack of detailed information regarding the potentially wide variability in GA technique, in addition to the significant evolution in GA, and the potential influence of modern GA technique on outcomes were also acknowledged [42].

Surprisingly, longer surgery duration was prognostic of greater recovery for the TKA group. It was, however, found to have the least prognostic value in this model. As surgery duration may be influenced by multiple factors including surgeon experience, anaesthetic technique, surgical approach, surgical technique, and complexity of surgical procedure, the clinical relevance of this particular finding is unclear.

In contrast, surgical approach was strongly prognostic of greater inpatient functional recovery in the THA group, making a difference of 4.7 points on the 36-point mILAS scale. This may be due to the muscle-sparing nature of the DAA and DSA compared to the PA THA, for which inpatient functional recovery was poorer. A systematic review [43] confirms that few studies have compared THA surgical approaches using inpatient function as an outcome. Achievement of early postoperative functional goals has been reported in favour of DAA compared to PA THA [16, 44, 45]. Recent guidelines, however, found inconclusive evidence regarding the effect of different surgical approaches on time to meet discharge criteria following THA in an enhanced recovery setting; adequately powered randomised controlled trials were recommended $[5,8]$. Presently, this study valuably adds to the evidence available to inform practice in this area. Overall, with regard to surgical factors, our results indicate that DAA or DSA for THA, use of GA only, and LIA use were all associated with greater levels of post-operative functional recovery on POD 2, and thus warrant consideration as key ERP components.

With respect to site of arthroplasty, a statistically significant difference in POD2 mILAS scores was found in favour of the THA group; however, this may be, in part, due to the significant difference identified in ASA grade distributions between the TKA and THA groups. Although the THA group had lower pre-operative 
Table 10 Association between individual potential prognostic factors and length of stay in overall cohort

\begin{tabular}{|c|c|c|}
\hline Potential prognostic factors & $\begin{array}{l}r_{S} \text { or } U, Z \text { values } \\
\text { IQR LOS (nights) for groups }\end{array}$ & $p$ value \\
\hline \multicolumn{3}{|l|}{ Patient-related factors } \\
\hline Gender ( 0 = female, 1 = male) & $\begin{array}{l}\text { 14685.0, }-1.022 \\
\text { IQR female (4.0-5.0), IQR male (4.0-5.0) }\end{array}$ & 0.31 \\
\hline Age & 0.20 & $<0.001^{* *}$ \\
\hline BMl & 0.06 & 0.29 \\
\hline ASA & 0.12 & $0.03^{*}$ \\
\hline $\mathrm{Hb}$ & -0.03 & 0.54 \\
\hline Living situation & 0.04 & 0.51 \\
\hline RAPT score & -0.27 & $<0.001^{* *}$ \\
\hline Pre-op pain (VAS) & 0.08 & 0.15 \\
\hline Pre-op patient-reported general health (EQ-5D VAS) & -0.11 & $0.03^{*}$ \\
\hline Pre-op patient-reported function (OKS/OHS) & -0.18 & $0.001^{* *}$ \\
\hline Pre-op function (mILAS) & 0.20 & $<0.001^{* *}$ \\
\hline Pre-op function (TUG) & 0.26 & $<0.001^{* *}$ \\
\hline Pre-op function (10mWT) & 0.21 & $<0.001^{* *}$ \\
\hline \multicolumn{3}{|l|}{ Surgical factors } \\
\hline Arthroplasty site $(0=\mathrm{THA}, 1=\mathrm{TKA})$ & $\begin{array}{l}\text { 12065.0, }-1.996 \\
\text { IQR THA (3.0-5.0), IQR TKA (4.0-5.0) }\end{array}$ & $0.05^{*}$ \\
\hline Robot-assisted surgery ( $0=$ no, $1=$ yes $)$ & $\begin{array}{l}5337.0,-0.690 \\
\text { IQR no }(4.0-5.0) \text {, IQR yes }(3.25-5.0)\end{array}$ & 0.49 \\
\hline GA only ( $0=$ no, $1=$ yes $)$ & $\begin{array}{l}\text { 10172.5, }-2.769 \\
\text { IQR no (4.0-5.0), IQR yes (3.0-5.0) }\end{array}$ & $0.006^{* *}$ \\
\hline GA and spinal anaesthesia ( $0=$ no, $1=$ yes $)$ & $\begin{array}{l}\text { 13215.0, }-2.419 \\
\text { IQR no (3.0-5.0), IQR yes (4.0-5.0) }\end{array}$ & $0.02^{*}$ \\
\hline Sedation and spinal anaesthesia ( $0=$ no, $1=$ yes $)$ & $\begin{array}{l}\text { 7972.0, }-0.373 \\
\text { IQR no (4.0-5.0), IQR yes (4.0-5.0) }\end{array}$ & 0.71 \\
\hline LIA use $(0=$ no, $1=$ yes $)$ & $\begin{array}{l}\text { 7150.0, }-2.398 \\
\text { IQR no (4.0-5.75), IQR yes (4.0-5.0) }\end{array}$ & $0.02^{*}$ \\
\hline PCA use $(0=$ no, $1=$ yes $)$ & $\begin{array}{l}\text { 9709.0, }-1.122 \\
\text { IQR no (4.0-5.0), IQR yes (4.0-6.0) }\end{array}$ & 0.26 \\
\hline Intra-articular catheter (TKA only) ( $0=$ no, $1=$ yes) & $\begin{array}{l}6671.0,-0.755 \\
\text { IQR no (4.0-5.0), IQR yes (4.0-5.0) }\end{array}$ & 0.45 \\
\hline Single-shot regional block (TKA only) $(0=$ no, $1=$ yes $)$ & $\begin{array}{l}\text { 2566.5, }-1.867 \\
\text { IQR no (4.0-5.0), IQR yes (4.0-6.0) }\end{array}$ & 0.06 \\
\hline Ambulatory regional block (TKA only) $(0=$ no, $1=$ yes $)$ & $\begin{array}{l}\text { 2437.0, }-0.720 \\
\text { IQR no (4.0-5.0), IQR yes (3.0-5.5) }\end{array}$ & 0.47 \\
\hline Surgical approach (THA only) $(0=\mathrm{PA}, 1=\mathrm{DAA}$ or DSA $)$ & $\begin{array}{l}975.5,-3.645 \\
\text { IQR PA }(4.0-5.0) \text {, IQR DAA or DSA (3.0-4.0) }\end{array}$ & $<0.001^{* *}$ \\
\hline Surgery duration & -0.03 & 0.52 \\
\hline Tourniquet duration (TKA only) & -0.02 & 0.94 \\
\hline Tourniquet pressure (TKA only) & -0.02 & 0.50 \\
\hline \multicolumn{3}{|l|}{ Post-operative factors } \\
\hline DOS mobilisation ( $0=$ no, $1=$ yes $)$ & $\begin{array}{l}\text { 10,659.0-2.443 } \\
\text { IQR no (4.0-6.0), IQR yes }(4.0-5.0)\end{array}$ & $0.02^{*}$ \\
\hline Incidence of post-operative progress barriers $(0=$ no, $1=$ yes $)$ & $\begin{array}{l}8482.5,-7.735 \\
\text { IQR no }(3.0-4.0), \text { IQR yes }(4.0-6.0)\end{array}$ & $<0.001^{* *}$ \\
\hline
\end{tabular}


Table 10 Association between individual potential prognostic factors and length of stay in overall cohort (Continued)

\begin{tabular}{llr}
\hline Potential prognostic factors & $\begin{array}{l}r_{\text {S }} \text { or } U, Z \text { values } \\
\text { IQR LOS (nights) for groups }\end{array}$ & $p$ value \\
\hline POD 2 mILAS & 0.54 & $<0.001^{* *}$ \\
POD 2 TUG & 0.31 & $<0.001^{* *}$ \\
POD 2 10mWT & 0.28 & $<0.001^{* *}$ \\
\hline
\end{tabular}

$p$ values were derived from Spearman's correlation or Mann-Whitney $U$ test, as appropriate for variable type

ASA American Society of Anaesthesiologists, BMI body mass index, DAA direct anterior approach, DSA direct superior approach, DOS day of surgery, EQ-5D VAS EuroQol-5 Dimension Visual Analogue Scale, GA general anaesthesia, $H b$ haemaglobin, IQR inter-quartile range, LIA local infiltration analgesia, $L O S$ length of stay, mILAS modified lowa Level of Assistance Scale, OKS Oxford Knee Score, OHS Oxford Hip Score, PA posterior approach, PCA patient-controlled analgesia, POD postoperative day, RAPT Risk Assessment and Prediction Tool, THA total hip arthroplasty, TKA total knee arthroplasty, TUG Timed Up and Go test, VAS visual analogue scale, $10 \mathrm{mWT}$ ten-metre walk test

*Statistical significance $p<0.05$ level

**Statistical significance $p<0.01$ level

comorbidity overall (Table 1), both arthroplasty groups had a median ASA grade of 2. Additionally, the THA group had a greater proportion of patients receiving GA only (also a significant prognostic factor for POD 2 mILAS scores); however, site of arthroplasty and use of GA only were both significant independent prognostic factors within the final prognostic model for the overall cohort. Few studies have investigated site of arthroplasty as a prognostic factor for early post-operative functional outcomes. Although methodological quality limited the generalisability of the results, significantly slower functional recovery was observed in TKA patients when compared to THA patients at 1 week post-operatively [46, 47].

Interestingly, several potentially modifiable patientrelated factors were significantly prognostic for POD 2 mILAS scores. These include pre-operative TUG time, RAPT score, and self-reported general health status (EQ-5D VAS). TUG time was the only prognostic factor to feature in each of the final models. Findings for the overall cohort indicate that every 5-s increase in time to complete the pre-operative TUG test equates to an increase of 2.25 points in the mean predicted POD 2 mILAS score, representing poorer functional recovery. This finding is relevant particularly for patients of lower pre-operative functional status and supports the available evidence for pre-operative conditioning. The prognostic value of pre-operative TUG time, specifically, has been supported by a strong level of evidence in TKA studies, but only limited evidence in studies of THA [9]. A further study, not included in the systematic review [9], also reported pre-operative TUG time in their final predictive model for functional recovery following THA [16].

Higher RAPT scores were strongly prognostic of greater POD 2 functional recovery in the THA model, such that a difference of 5 points on the RAPT would be associated with a mILAS difference of 4.7 points (equal to that associated with a change in THA surgical approach). Developed as a screening tool to predict discharge destination following THA and TKA, the RAPT score assigns values to the patient's age, sex, preoperative exercise tolerance, the necessity for a mobility aid or community services, and social support upon discharge [48]. Although the RAPT score is primarily determined by non-modifiable factors, scoring of the exercise tolerance item and potentially the mobility aid item may be improved by optimising pre-operative function. The RAPT has only been identified in one other study as a potential predictor for early functional recovery [16] and was not included in their final prediction model.

Pre-operative patient-reported general health status had limited prognostic value in the models for both the overall cohort and TKA group. As expected, poorer preoperative general health was associated with lower levels of post-operative functional recovery; however, a difference of 20 points on the EQ-5D VAS would be required to effect a change of 1.0 and 1.8 points in mILAS score for the overall cohort and TKA group, respectively. Furthermore, only a weak, statistically significant positive correlation was identified between ASA grade and POD 2 mILAS scores. This finding is in contrast with the strong and moderate levels of evidence for TKA and for THA, respectively, previously reported for an association between comorbidity status (ASA grade) and early postoperative functional outcomes [9].

Slower functional recovery was apparent for patients of older age and female sex in the overall cohort and TKA group. To date, two systematic reviews $[9,49]$ have reported conflicting evidence regarding an association between age and early post-operative functional recovery following THA [9, 49] and TKA [9]. Similarly, conflicting evidence was found for sex $[9,49]$ in studies of THA, whilst limited evidence supported an association between female sex and reduced early post-operative functional recovery in TKA studies [9].

Taken together, the identification of these patientrelated prognostic factors supports pre-operative screening to identify patients of older age, female sex, poorer pre-operative health and functional status, and scoring lower on the RAPT as they may be less likely to achieve an accelerated recovery per many ERP. The use of these 
prognostic models during pre-operative screening may facilitate organisational efficiency by assisting in the prediction of patient flow. Telehealth may be a viable option for pre-operative screening in patients with reduced access to services [50] and avoids a significant cost burden to both patients and healthcare organisations [51]. Prehabilitation may significantly impact pre-operative TUG time, as well as exercise tolerance, thus potentially improving RAPT score and general well-being. As per the prognostic model, improvement in pre-operative function would result in changes to predicted early postoperative functional recovery.

Few studies, to our knowledge, have linked inpatient post-operative function to longer-term outcomes. Our results are similar to Bade et al. [18] who found acute functional performance to be predictive of functional performance at 6 months post-operatively following TKA, although pre-operative functional performance was found to be a stronger predictor. The small association between POD 2 mILAS scores and patientreported functional outcomes assessed via OKS and OHS at 6 months post-operatively found for the overall cohort and the TKA sub-group warrants further research with larger cohorts. Inpatient function does not appear to be associated with longer-term general health. However, the EQ-5D VAS requires the respondent to rate their health "today", thus providing a very specific "snap-shot" of health status, which may be influenced by numerous factors. In addition, although a positive correlation existed between 6 months post-operative OHS and OKS scores and EQ-5D VAS assessed at the same time, $44.1 \%$ of the overall sub-group reported health conditions other than the arthroplasty undertaken during the study impacted their EQ-5D VAS. Moreover, general health ratings remained largely static preoperatively to post-operatively despite large improvements in joint-specific functional assessments (OHS and OKS).

Inpatient functional performance was significantly correlated with LOS in the overall cohort, and similar results have been reported by Poitras et al. [15]. Higher POD 2 mILAS scores may be a useful clinical indicator of patients at risk of prolonged LOS, enabling prompt post-operative planning for patients who are recovering function more slowly than expected. Weak correlations between all patient-related factors and LOS were identified in this study. This is in contrast to previously reported strong level evidence for higher ASA grade, greater number of comorbidities, and presence of heart or lung disease as predictors of longer LOS following THA [49]. THA surgical approach was the only surgical factor in this study to be moderately correlated with LOS. PA THA was associated with longer LOS than DAA or DSA. A study of 5341 THA procedures also found patients who received DAA or DSA THA had statistically significantly shorter LOS and a higher rate of discharge directly home [52].

Strengths of this study include the spectrum of patient and surgical prognostic factors and the use of standardised, validated functional performance measures which are clinically relevant, easily integrated into routine post-operative assessment, and appropriate to the time point at which they were assessed. The mILAS [11] was selected as the primary outcome measure as it incorporates tasks reflective of the ADL necessary to safely discharge home [53]. Versions of the mILAS have been used in similar studies; however, its implementation is heterogeneous and has thus limited the comparison of results. The study cohort is believed to be reflective of the general arthroplasty population, with few exclusion criteria implemented. To control for the potential influence of patient expectation on LOS, only patients who attended pre-admission clinic and received pre-operative education were included in the study.

There are several limitations of this study. The prognostic models are based on data from a single centre which has implemented a partially standardised ERP. To increase generalisability, the models require internal and external validation preferably in a multicentre study, similarly involving non-standardised ERP. POD 2 was chosen as the time point to assess functional recovery to enable comparisons with studies examining ERP outcomes where a LOS of 2 days has been reported. However, with THA and TKA being performed as ambulatory surgery in some organisations, further studies with earlier post-operative assessment time points are needed. While LIA use was identified as a significant prognostic factor, variations in site of administration, volume, and content of LIA administered were not accounted for in this study. Similarly, differences in dosage parameters, content, or duration of PCA use were not addressed; thus, further research is required to determine the impact of these variables. The impact of robotic-assisted surgery could not be fully assessed due to its application in only a small volume of the study cohort. Currently, in this facility, robot-assisted surgery is primarily used for uni-compartmental knee arthroplasty which, to maximise homogeneity, was not included in this cohort. Due to insufficient case numbers, the role of muscle-sparing approaches for TKA was also not able to be assessed; thus, these surgical factors warrant further research. Further research is also necessary to determine cut-off points for age, pre-operative TUG time, pre-operative EQ-5D VAS, and RAPT score to further guide pre-operative screening. 
Due to time constraints, only the first half of the study cohort was assessed for longer-term functional outcomes. Due to the natural evolution of enhanced recovery techniques during the period of data collection, this sample may have varied slightly, with regard to surgical factors, from the remainder of the cohort. To reduce the potential for missing data, participants were not required to attend the hospital for assessment of longer-term functional outcomes. Therefore, inpatient function and longer-term functional outcomes could not be directly compared due to the variance in outcome measures assessed. However, inpatient function and longer-term functional outcomes could both be directly compared to pre-operative functional outcomes.

Validated tools for assessing short-term postoperative function following lower limb arthroplasty are lacking $[11,54]$. In the absence of a gold standard for evaluating functional recovery in acute hospital inpatients, the mILAS [11] was used in this study. However, a 30-point version of the mILAS has recently been described and validated by Elings et al. [55] which may be of greater clinical relevance as it only assesses functional tasks. Implementation of a valid, standardised performance measure, such as this newer version of the mILAS, would assist in objective assessment of post-operative functional recovery, identification of patients at risk of prolonged LOS, and evaluation of ERP interventions [54], and also facilitate the benchmarking of patient-centred outcomes between organisations.

\section{Conclusions}

This study identified several patient-related and surgical factors prognostic for early post-operative functional recovery. Patient-related factors included in the final prognostic models for the overall cohort and TKA group were age, sex, pre-operative general health status, and pre-operative TUG time. Preoperative TUG time and RAPT score were prognostic in the final model for the THA group. Surgical prognostic factors for the overall cohort and TKA group were use of GA only, LIA use and PCA use, with the addition of arthroplasty site in the model for the overall cohort, and surgery duration in the TKA group. Surgical approach was the only surgical prognostic factor in the model for the THA group. THA surgery was prognostic for greater functional recovery at POD 2 than TKA surgery. Several patient-related, surgical, and post-operative factors were associated with acute hospital LOS. A correlation was found between functional ability at POD 2 and OKS/OHS, assessed at 6 months postoperatively. Validation of these findings is required, and assessment time points earlier in the postoperative period could be implemented. Prognostic models may facilitate the prediction of inpatient flow thus optimising organisational efficiency. In addition, surgical prognostic factors warrant consideration as potentially key ERP elements, associated with early functional recovery. Standardised functional outcome measures are needed to evaluate patient-centred ERP outcomes and to facilitate the processes of benchmarking, auditing, and improving ERP.

\section{Appendix 1: Two-stage process for exclusion of patients with cognitive impairment}

1st stage: Pre-admission screening

Patients were screened by an occupational therapist (OT) during their pre-admission interview. Initial cognitive screening occurred via the OT's observation of the patient during the interview as well as the following screening question. "Do you have any difficulties with your thinking or memory?"

If a Yes response was elicited with the above cognitive screening question:

The patient was flagged by the OT, and the MiniMental State Examination (MMSE) [10] was implemented by the patient's treating physiotherapist on the acute orthopaedic ward during hospital admission. Patients scoring 23 or less, out of a maximum possible score of 30 (indicating cognitive impairment), were subsequently excluded from the research study, and on that basis, their data was not included in the data set or analysis.

If a No response was elicited with the above cognitive screening question:

The patient was considered eligible to consent to participate in the research study. However, the OT flagged any patients whom exhibited signs of cognitive impairment during the interview despite answering "No" to the screening question, and the MMSE was performed by the patient's treating physiotherapist on the acute orthopaedic ward during hospital admission. Patients scoring 23 or less were subsequently excluded from the research study, and on that basis, their data was not included in the data set or analysis.

\section{2nd stage: Noted poor post-operative progression}

Any research study participant identified by their treating physiotherapist as not following a usual postoperative recovery due to possible cognitive impairment undertook an MMSE on the acute orthopaedic ward. Patients scoring 23 or less were subsequently excluded from the research study, and on that basis, their data was not included in the data set or analysis. 


\section{Appendix 2}

Table 11 Modified lowa Level of Assistance Scale (Kimmel et al. [12])

\begin{tabular}{|c|c|c|c|c|}
\hline Score & $\begin{array}{l}\text { Amount of } \\
\text { assistance }\end{array}$ & Items 1-4 & Item 5 & Item 6 \\
\hline 0 & Independent & $\begin{array}{l}\text { No assistance or supervision is necessary to safely perform the activity (with or } \\
\text { without an assistive device/aid) }\end{array}$ & $>40 \mathrm{~m}$ & No assistive device \\
\hline 1 & Standby & Nearby supervision is required; no contact is necessary & $26-40 m$ & 1 stick or crutch \\
\hline 2 & Minimal & $\begin{array}{l}\text { One point of contact is necessary, including helping with the application of the } \\
\text { assistive device, getting legs on/off leg rest, and stabilising the assistive device }\end{array}$ & $10-25 \mathrm{~m}$ & 2 sticks \\
\hline 3 & Moderate & Two points of contact needed (1-2 people) & $5-9 m$ & 2 elbow crutches \\
\hline 4 & Maximal & Significant support-3 or more points of contact (> 1 person) & $3-4 m$ & 2 axillary crutches \\
\hline 5 & Failed & Attempted activity but failed with maximal assistance & $2 m$ & Frame (standard or wheelie) \\
\hline 6 & Not tested & Test was not attempted due to medical reasons or reasons of safety & $<2 \mathrm{~m}$ & $\begin{array}{l}\text { Gutter/platform frame, standing } \\
\text { lifter, hoist, or unsafe to use aid }\end{array}$ \\
\hline
\end{tabular}

Modified lowa Level of Assistance Scale items: 1-supine to sitting on the edge of the bed, 2-sit to stand, 3-walking, 4-negotiation of one step, 5-walking distance, 6-assistive device used

\section{Appendix 3}

Table 12 The Wesley Hospital Enhanced Recovery Pathway (ERP) discharge criteria for THA and TKA

\begin{tabular}{ll}
\hline Allied health & Independent with transfers in/out of bed and chair \\
& Walking independently with aid \\
& Able to negotiate stairs (with supervision, if needed) \\
& Equipment and follow-up physiotherapy organised \\
Nursing & Showering \\
& Toileting (bowels opened) \\
& Pain adequately controlled \\
& Wound and dressings reviewed (as appropriate) \\
& Discharge Planning (e.g. services organised if \\
Patient & Applicable, support person contacted) \\
\hline
\end{tabular}

\section{Abbreviations}

ADL: Activities of daily living; ASA: American Society of Anaesthesiologists; BMI: Body mass index; DAA: Direct anterior approach; DSA: Direct superior approach; DOS: Day of surgery; EQ-5D VAS: EuroQol 5 Dimension Visual Analogue Scale; ERP: Enhanced Recovery Pathway; GA: General anaesthesia; Hb: Haemaglobin; IQR: Inter-quartile range; LIA: Local infiltration analgesia; LOS: Length of stay; MDC: Minimal detectable change; MIC: Minimal important change; mILAS: Modified lowa Level of Assistance Scale; MMSE: Mini-Mental State Examination; OHS: Oxford Hip Score; OKS: Oxford Knee Score; OT: Occupational therapist; PA: Posterior approach; PCA: Patientcontrolled analgesia; POD: Post-operative day; PROM: Patient-reported outcome measure; THA: Total hip arthroplasty; TKA: Total knee arthroplasty; TUG: Timed Up and Go; VAS: Visual analogue scale; 10mWT: Ten-metre walk test

\section{Acknowledgements}

The authors wish to acknowledge Ross Ferguson, Lisa Haigh, all physiotherapy staff involved in data collection, the staff of the orthopaedic wards and pre-admission clinic, Dr. Kate Brunello, Dr. Rohan Brunello, and Dr. Bjorn Smith at The Wesley Hospital, Brisbane, Australia, and Evelyn Rathbone, Bond University, Gold Coast, Australia, for their encouragement, support, and contributions.

\section{Authors' contributions}

Conception/planning: NHS, RP, WH. Data collection: NHS. Statistical analysis: NHS, RP, WH, VS. Results: NHS, RP. Discussion/conclusion: NHS, RP. Review/ editing: NHS, RP, WH, VS, JF. The authors read and approved the final manuscript.

\section{Authors' information}

Nicola Hewlett-Smith is a Senior Orthopaedic physiotherapist at The Wesley Hospital, Brisbane.

\section{Funding}

This research was supported by an Australian Government Research Training Program Scholarship.

\section{Availability of data and materials}

Access to the dataset generated and analysed during the current study, subject to necessary ethics approvals, can be obtained by contacting the corresponding author (NHS). This dataset is not publicly available due to the presence of information that could compromise research participant privacy/ consent.

\section{Ethics approval and consent to participate}

Ethics approval was obtained for this study from the Uniting Care Human Research Ethics Committee (HREC no. 2016.09.187) and Bond University Human Research Ethics Committee (HREC no. 15685). All study participants provided written informed consent. 


\section{Consent for publication}

Not applicable

\section{Competing interests}

The authors declare that they have no competing interests.

\section{Author details}

${ }^{1}$ Faculty of Health Sciences and Medicine, Bond University, Gold Coast, Australia. ${ }^{2}$ Nicola Hewlett-Smith Allied Health Department, The Wesley Hospital, PO Box 499, Brisbane 4066, Australia. ${ }^{3}$ School of Community Health, Charles Sturt University, Albury, Australia.

\section{Received: 29 May 2020 Accepted: 31 July 2020}

Published online: 27 August 2020

\section{References}

1. Ackerman IN, Bohensky MA, Zomer E, Tacey M, Gorelik A, Brand CA, De Steiger R. The projected burden of primary total knee and hip replacement for osteoarthritis in Australia to the year 2030. BMC Musculoskelet Disord. 2019;20(1):90. https://doi.org/10.1186/s12891-019-2411-9.

2. Australian Orthopaedic Association National Joint Replacement Registry (AOANJRR). Hip, knee and shoulder arthroplasty: 2019 Annual Report. Pages 74 and 209. Accessed: 30 March 2020. https://aoanjrr.sahmri.com/ documents/10180/668596/Hip\%2C+Knee+\%26+Shoulder+Arthroplasty/c2 87d2a3-22df-a3bb-37a2-91e6c00bfcf0.

3. Kehlet $\mathrm{H}$. Painless and risk-free surgery--a vision of the future? Ugeskr Laeger. 1994;56(23):3468-9 ISSN:0041-5782.

4. Husted H. Fast-track hip and knee arthroplasty: clinical and organizational aspects. Acta Orthop. 2012;83(Suppl 346):1-39. https://doi.org/10.3109/ 17453674.2012 .700593

5. Wainwright TW, Gill M, McDonald DA, Middleton RG, Reed M, Sahota O, Yates $\mathrm{P}$, Ljungqvist $\mathrm{O}$. Consensus statement for perioperative care in total hip replacement and total knee replacement surgery: Enhanced Recovery After Surgery: ERAS Society recommendations. Acta Orthop. 2020;91(1):3-19. https://doi.org/10.1080/17453674.2019.1683790.

6. Mawdsley MJ, Baker PN, Desai A, Green RN, Jevons L. Regional uptake an variations in orthopaedic enhanced recovery pathways in knee and hip total arthroplasty. J Perioper Pract. 2016;26(5):118-22. https://doi.org/10. 1177/175045891602600505.

7. Soffin EM, YaDeau JT. Enhanced recovery after surgery for primary hip and knee arthroplasty: a review of the evidence. Br J Anaesth. 2016;117(suppl 3): iii62-72. https://doi.org/10.1093/bja/aew362.

8. Galbraith AS, McGloughlin E, Cashman J. Enhanced recovery protocols in total joint arthroplasty: a review of the literature and their implementation. Ir J Med Sci. 2018;187(1):97-109. https://doi.org/10. 1007/s11845-017-1641-9

9. Hewlett-Smith N, Pope R, Furness J, Simas V, Hing W. Prognostic factors for inpatient functional recovery following total hip and knee arthroplasty: a systematic review. Acta Orthop. 2020:1-6. https://doi.org/10.1080/17453674. 2020.1744852

10. Folstein MF, Folstein SE, McHugh PR. Mini-Mental State Examination. J Psychiat Res. 1975;12:189-98.

11. Kimmel LA, Elliott JE, Sayer JM, Holland AE. Assessing the reliability and validity of a physical therapy functional measurement tool-the modified lowa Level of Assistance Scale-in acute hospital inpatients. Phys Ther. 2016; 96(2):176-82. https://doi.org/10.2522/ptj.20140248.

12. Podsiadlo D, Richardson S. The timed "Up \& Go": a test of basic functional mobility for frail elderly persons. J Am Geriatr Soc. 1991;39(2):142-8. https:// doi.org/10.1111/j.1532-5415.1991.tb01616.x.

13. Karpman C, Lebrasseur NK, Depew ZS, Novotny PJ, Benzo RP. Measuring gait speed in the out-patient clinic: methodology and feasibility. Respiratory care. 2014;59(4):531-7. https://doi.org/10.4187/respcare.02688.

14. Yuksel E, Kalkan S, Cekmece S, Unver B, Karatosun V. Assessing minimal detectable changes and test-retest reliability of the timed up and go test and the 2-minute walk test in patients with total knee arthroplasty. J Arthroplasty. 2017;32(2):426-30. https://doi.org/10.1016/ j.arth.2016.07.031

15. Poitras S, Wood KS, Savard J, Dervin GF, Beaule PE. Predicting early clinical function after hip or knee arthroplasty. Bone Joint Res. 2015:4(9):145-51. https://doi.org/10.1302/2046-3758.49.2000417.
16. Oosting E, Hoogeboom TJ, Appelman-de Vries SA, Swets A, Dronkers JJ, van Meeteren NL. Preoperative prediction of inpatient recovery of function after total hip arthroplasty using performance-based tests: a prospective cohort study. Disabil Rehabil. 2016;38(13):1243-9. https://doi.org/10.3109/09638288. 2015.1076074

17. Nankaku M, Tsuboyama T, Akiyama H, Kakinoki R, Fujita $Y$, Nishimura J, Yoshioka Y, Kawai H, Matsuda S. Preoperative prediction of ambulatory status at 6 months after total hip arthroplasty. Phys Ther. 2013;93(1):88-93. https://doi.org/10.2522/ptj.20120016.

18. Bade MJ, Kittelson JM, Kohrt WM, Stevens-Lapsley JE. Predicting functional performance and range of motion outcomes after total knee arthroplasty. Am J Phys Med Rehabil. 2014;93(7):579-85. https://doi.org/10.1097/phm. 0000000000000065.

19. Peters DM, Fritz SL, Krotish DE. Assessing the reliability and validity of a shorter walk test compared with the 10-Meter Walk Test for measurements of gait speed in healthy, older adults. J Geriatr Phys Ther. 2013;36(1):24-30. https://doi.org/10.1519/JPT.0b013e318248e20d.

20. Viccaro $\sqcup$, Perera S, Studenski SA. Is timed up and go better than gait speed in predicting health, function, and falls in older adults? J Am Geriatr Soc. 2011;59(5):887-92. https://doi.org/10.1111/j.1532-5415.2011.03336.x.

21. Dawson J, Fitzpatrick R, Carr A, Murray D. Questionnaire on the perceptions of patients about total hip replacement. J Bone Joint Surg Br. 1996;78(2): 185-90 ISSN:0301-620x.

22. Dawson J, Fitzpatrick R, Murray D, Carr A. Questionnaire on the perceptions of patients about total knee replacement. J Bone Joint Surg Br. 1998;80(1): 63-9. https://doi.org/10.1302/0301-620x.80b1.7859.

23. EuroQol Group. 2009. Effective_Australia (English) EQ-5D-5L Paper Self complete Version 1.0. https://euroqol.org/support/how-to-obtain-eq-5d/ Accessed March 2018.

24. Murray DW, Fitzpatrick R, Rogers K, Pandit H, Beard DJ, Carr AJ, Dawson J. The use of the Oxford hip and knee scores. J Bone Joint Surg Br. 2007;89(8): 1010-4. https://doi.org/10.1302/0301-620x.89b8.19424.

25. Beard DJ, Harris K, Dawson J, Doll H, Murray DW, Carr AJ, Price AJ. Meaningful changes for the Oxford hip and knee scores after joint replacement surgery. J Clin Epidemiol. 2015;68(1):73-9. https://doi.org/10. 1016/j.jclinepi.2014.08.009.

26. Dawson J, Fitzpatrick R, Churchman D, Verjee-Lorenz A, Clayson D. Oxford Hip Score (OHS) user manual, version 1.0 August 2010. Oxford University Innovation Limited. https://innovation.ox.ac.uk/outcome-measures/oxfordhip-score-ohs/ Accessed Mar 2018.

27. Dawson J, Fitzpatrick R, Churchman D, Verjee-Lorenz A, Clayson D. Oxford Knee Score (OKS) User Manual, Version 1.0 August 2010. Oxford University Innovation Limited. https://innovation.ox.ac.uk/outcome-measures/oxfordknee-score-oks/. Accessed March 2018.

28. Clement N. Patient factors that influence the outcome of total knee replacement: a critical review of the literature. OA Orthopaedics. 2013;1(2): 11. https://doi.org/10.13172/2052-9627-1-2-697.

29. Husted $H$, Holm G, Jacobsen S. Predictors of length of stay and patient satisfaction after hip and knee replacement surgery: fast-track experience in 712 patients. Acta Orthop. 2008;79(2):168-73. https://doi.org/10.1080/ 17453670710014941

30. Husted H, Hansen HC, Holm G, Bach-Dal C, Rud K, Andersen KL, Kehlet H. What determines length of stay after total hip and knee arthroplasty? A nationwide study in Denmark. Arch Orthop Trauma Surg. 2010;130(2):263-8. https://doi.org/10.1007/s00402-009-0940-7.

31. Husted H, Lunn TH, Troelsen A, Gaarn-Larsen L, Kristensen BB, Kehlet H. Why still in hospital after fast-track hip and knee arthroplasty? Acta Orthop. 2011; 82(6):679-84. https://doi.org/10.3109/17453674.2011.636682.

32. den Hertog A, Gliesche K, Timm J, Mühlbauer B, Zebrowski S. Pathwaycontrolled fast-track rehabilitation after total knee arthroplasty: a randomized prospective clinical study evaluating the recovery pattern, drug consumption, and length of stay. Arch Orthop Trauma Surg. 2012:132(8): 1153-63. https://doi.org/10.1007/s00402-012-1528-1.

33. Napier RJ, Spence D, Diamond O, O'Brien S, Walsh T, Beverland DE. Modifiable factors delaying early discharge following primary joint arthroplasty. Eur J Orthop Surg Traumatol. 2013;23(6):665-9. https://doi.org/ 10.1007/s00590-012-1053-5.

34. Flings J, van der Sluis G, Goldbohm RA, Garre FG, De Gast A, Hoogeboom T, Van Meeteren NL. Development of a risk stratification model for delayed inpatient recovery of physical activities in patients undergoing total hip 
replacement. J Orthop Sports Phys Ther. 2016;46(3):135-43. https://doi.org/ 10.2519/jospt.2016.6124.

35. Graham JE, Ostir GV, Fisher SR, Ottenbacher KJ. Assessing walking speed in clinical research: a systematic review. J Eval Clin Pract. 2008;14(4):552-62. https://doi.org/10.1111/j.1365-2753.2007.00917.x.

36. Cohen J. Statistical power analysis for the behavioral sciences. 2nd ed. Hillsdale: L. Erlbaum Associates; 1988.

37. Hojer Karlsen AP, Geisler A, Petersen PL, Mathiesen O, Dahl JB. Postoperative pain treatment after total hip arthroplasty: a systematic review. Pain. 2015; 156(1):8-30. https://doi.org/10.1016/j.pain.0000000000000003.

38. Karlsen AP, Wetterslev M, Hansen SE, Hansen MS, Mathiesen O, Dahl JB. Postoperative pain treatment after total knee arthroplasty: a systematic review. PLoS One. 2017;12(3):e0173107. https://doi.org/10.1371/journal.pone. 0173107.

39. Malviya A, Martin K, Harper I, Muller SD, Emmerson KP, Partington PF, Reed MR. Enhanced recovery program for hip and knee replacement reduces death rate. Acta Orthop. 2011;82(5):577-81. https://doi.org/10.3109/ 17453674.2011.618911

40. Scott NB, McDonald D, Campbell J, Smith RD, Carey AK, Johnston IG, James KR, Breusch SJ. The use of enhanced recovery after surgery (ERAS) principles in Scottish orthopaedic units--an implementation and follow-up at 1 year, 2010-2011: a report from the Musculoskeletal Audit, Scotland. Arch Orthop Trauma Surg. 2013;133(1):117-24. https://doi.org/10.1007/s00402-012-1619-z.

41. Johnson RL, Kopp SL, Burkle CM, Duncan CM, Jacob AK, Erwin PJ, Murad $\mathrm{MH}$, Mantilla CB. Neuraxial vs general anaesthesia for total hip and total knee arthroplasty: a systematic review of comparative-effectiveness research. Br J Anaesth. 2016;116(2):163-76. https://doi.org/10.1093/bja/aev455.

42. Memtsoudis SG, Cozowicz C, Bekeris J, Bekere D, Liu J, Soffin EM, Mariano EJ, Johnson RL, Hargett MJ, Lee BH, et al. Anaesthetic care of patients undergoing primary hip and knee arthroplasty: consensus recommendations from the International Consensus on Anaesthesia-Related Outcomes after Surgery group (ICAROS) based on a systematic review and meta-analysis. Br J Anaesth. 2019;123(3):269-87. https://doi.org/10.1016/j.bja. 2019.05.042

43. Jia F, Guo B, Xu F, Hou Y, Tang X, Huang L. A comparison of clinical, radiographic and surgical outcomes of total hip arthroplasty between direct anterior and posterior approaches: a systematic review and meta-analysis. Hip Int. 2019;29(6):584-96. https://doi.org/10.1177/1120700018820652.

44. Barrett WP, Turner SE, Leopold JP. Prospective randomized study of direct anterior vs postero-lateral approach for total hip arthroplasty. J Arthroplasty. 2013;28(9):1634-8. https://doi.org/10.1016/j.arth.2013.01.034

45. Rodriguez JA, Deshmukh AJ, Rathod PA, Greiz ML, Deshmane PP, Hepinstall MS, Ranawat AS. Does the direct anterior approach in THA offer faster rehabilitation and comparable safety to the posterior approach? Clin Orthop Relat Res. 2014:472(2):455-63. https://doi.org/10.1007/s11999-013-3231-0.

46. Kennedy DM, Hanna SE, Stratford PW, Wessel J, Gollish JD. Preoperative function and gender predict pattern of functional recovery after hip and knee arthroplasty. J Arthroplasty. 2006;21(4):559-66. https://doi.org/10.1016/j, arth.2005.07.010.

47. Kennedy DM, Stratford PW, Robarts S, Gollish JD. Using outcome measure results to facilitate clinical decisions the first year after total hip arthroplasty. J Orthop Sports Phys Ther. 2011;41(4):232-9. https://doi.org/10.2519/jospt. 2011.3516.

48. Oldmeadow LB, McBurney H, Robertson VJ. Predicting risk of extended inpatient rehabilitation after hip or knee arthroplasty. J Arthroplasty. 2003: 18(6):775-9. https://doi.org/10.1016/s0883-5403(03)00151-7.

49. Elings J, Hoogeboom TJ, van der Sluis G, van Meeteren NL. What preoperative patient-related factors predict inpatient recovery of physical functioning and length of stay after total hip arthroplasty? A systematic review. Clin Rehabil. 2015;29(5):477-92. https://doi.org/10.1177/ 0269215514545349.

50. Westby MD, Backman CL. Patient and health professional views on rehabilitation practices and outcomes following total hip and knee arthroplasty for osteoarthritis: a focus group study. BMC Health Serv Res. 2010;10:119. https://doi.org/10.1186/1472-6963-10-119.

51. Fusco F, Turchetti G. Telerehabilitation after total knee replacement in Italy: cost-effectiveness and cost-utility analysis of a mixed telerehabilitationstandard rehabilitation programme compared with usual care. BMJ Open. 2016;6(5):e009964. https://doi.org/10.1136/bmjopen-2015-009964.

52. Siljander MP, Whaley JD, Koueiter DM, Alsaleh M, Karadsheh MS. Length of stay, discharge disposition, and 90-day complications and revisions following primary total hip arthroplasty: a comparison of the direct anterior, posterolateral, and direct superior approaches. J Arthroplasty. 2020. https://doi.org/10.1016/j.arth.2020.01.082.

53. Shields RK, Enloe LJ, Evans RE, Smith KB, Steckel SD. Reliability, validity, and responsiveness of functional tests in patients with total joint replacement. Phys Ther. 1995;75(3):169-76; discussion 76-9. https://doi.org/10.1093/ptj/75. 3.169

54. Poitras S, Wood KS, Savard J, Dervin GF, Beaule PE. Assessing functional recovery shortly after knee or hip arthroplasty: a comparison of the clinimetric properties of four tools. BMC Musculoskelet Disord. 2016;17(1): 478. https://doi.org/10.1186/s12891-016-1338-7.

55. Elings J, Zoethout S, Ten Klooster PM, van der Sluis G, van Gaalen SM, van Meeteren NLU, Hoogeboom TJ. Advocacy for use of the modified lowa Level of Assistance Scale for clinical use in patients after hip replacement: an observational study. Physiotherapy. 2019;105(1):108-13. https://doi.org/ 10.1016/j.physio.2018.06.002

\section{Publisher's Note}

Springer Nature remains neutral with regard to jurisdictional claims in published maps and institutional affiliations.
Ready to submit your research? Choose BMC and benefit from:

- fast, convenient online submission

- thorough peer review by experienced researchers in your field

- rapid publication on acceptance

- support for research data, including large and complex data types

- gold Open Access which fosters wider collaboration and increased citations

- maximum visibility for your research: over $100 \mathrm{M}$ website views per year

At $\mathrm{BMC}$, research is always in progress.

Learn more biomedcentral.com/submissions 